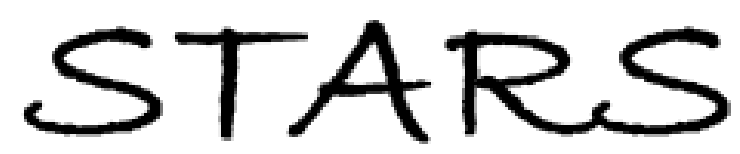

University of Central Florida

STARS

Faculty Scholarship and Creative Works

10-1-2013

\title{
Tourism Specialization and Economic Output in Small Islands
}

Robertico R. Croes

University of Central Florida, robertico.croes@ucf.edu

Part of the Hospitality Administration and Management Commons, and the Tourism and Travel Commons

Find similar works at: https://stars.library.ucf.edu/ucfscholar

University of Central Florida Libraries http://library.ucf.edu

This Paper is brought to you for free and open access by STARS. It has been accepted for inclusion in Faculty Scholarship and Creative Works by an authorized administrator of STARS. For more information, please contact STARS@ucf.edu.

\section{Original Citation}

Croes, R. (2013). Tourism specialization and economic output in small island destinations. Tourism Review, 68(4), 34-48.

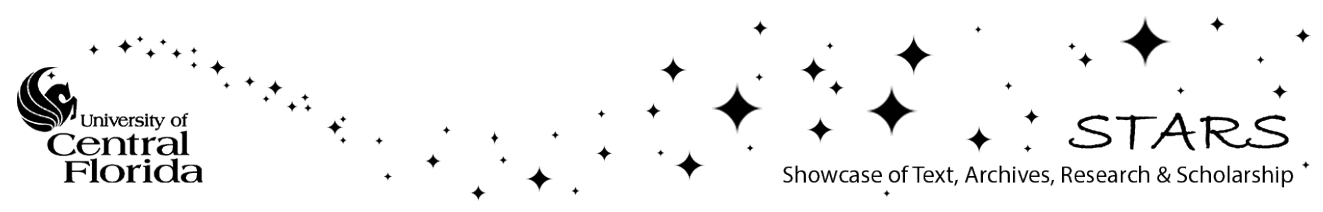


Croes, R. (2013). Tourism specialization and economic output in small island destinations. Tourism Review, 68(4), 34-48.

\title{
TOURISM SPECIALIZATION AND ECONOMIC OUTPUT IN SMALL ISLANDS
}

\begin{abstract}
Purpose: This study investigates growth differentials among small islands and the impact of tourism specialization on the growth and the economic performance of small islands.
\end{abstract}

Design/ methodology/approach: The study is based on trade theory and uses data from a panel of small islands for 1995-2007. It applies panel regression and standard time series methods combined with a qualitative approach.

Findings: Small islands experienced stronger basic patterns of growth than many developed countries, especially where economies of scale are not an issue. The findings further suggest that tourism specialization is not harmful to growth, and, in lieu of technological gaps and resource limitations, tourism specialization is a sound option. Size, a lack of complete sovereignty or independence and export orientation do not seem to affect the variance in the real per capita GDP at a greater degree. Finally, small islands may leverage returns to scale in global markets.

Research limitations: While tourism specialization is assumed to enhance growth, in the case of small island destinations, the study did not formally test whether increased terms-of-trade may be perpetually improved.

Practical implications: The study prompted four policy suggestions: (1) small island economies should engage in tourism specialization; (2) small island economies should allocate more resources to the tourism industry than other economic sectors; (3) the success of tourism specialization does not depend exclusively on comparative advantage; and (4) institutional realities and path dependence may play a role in economic performance.

Social implications: The crafting of an inclusive system could create social and political instability as those who have benefited from a closed tourism system may resist institutional changes and business practices.

Originality/value: The originality of this study lies in the detection of a paradox in mainstream economics that indicates that small islands may not enjoy sustained economic growth. The detection led to a surprising discovery that tourism specialization may propel growth. The value of the study is twofold: theoretical value is added by suggesting a reconceptualization of the construct capital; and, practical value is strengthened in the sense that tourism specialization may only work under a condition where upon tourism offerings command higher prices than other commodities.

Key words: size, tourism specialization, economic growth, small islands, terms-of-trade. 


\section{Introduction}

Investment opportunities for any tourist destination rely on growth potential. Understanding the determinants of growth therefore is crucial in any discussion pertaining to the future. Adam Smith (1976) taught that economic productivity and growth are defined by the size of the market. Larger markets in Smith's view are related to division of labor, which facilitates the economic advantage of labor specialization. Labor specialization in turn spawns economic efficiency and higher productivity. Compared to smaller markets, bigger markets are more likely to realize higher productivity levels and hence faster economic growth rates through increasing returns to scale, and spillovers in knowledge and network effects. Smaller economies and markets, on the other hand, inhibit labor specialization because people have to perform most or all of their own tasks. However, the degree of specialization is linked to demand moreover investing resources. Investing resources in specialization is justified only if demand is adequate to recover the cost of investment.

The negative connotation of small size is premised on the neoclassical framework, which traditionally has equated small size with insufficiency: population, labor, scale, entrepreneurship and capital, and resources in general. The insufficiency of resources, according to this perspective, affects the performance of these entities in such a way that they cannot achieve economies of scale. In addition, insufficient resources and the small size of the market may inhibit sufficient profitable opportunities thereby negatively affecting competition (Croes, 2006; 2011). To reduce and mitigate these constraints, small economies have employed trade as a mechanism to enlarge their domestic markets and infuse more competition. The high degree of openness and integration with the global market -- a hallmark of small countries -- has been perceived, however, as a sign of dependency and vulnerability, which might adversely affect growth performance.

Typically, studies investigating growth compared income levels and growth rates among small and large countries and the significant challenges that they face (Armstrong and Read, 2001; Balaguer and Cantavella-Jorda, 2002; Briguglio, 1995; Read, 2004; Selwyn, 1975; Shand, 1980; Srinivasan, 1986). These studies, while rigorous in their methodology design and contributions to the literature, are not particularly relevant to small island destinations due to their special characteristics and vulnerabilities (Croes, 2011; Jackson et al., 2013; Seetanah, 2011). In addition, the relationship between trade and growth does not seem straightforward. Findings from the studies conducted by Barro (1991), Sachs and Warner (1995), Frankel and Romer (1999), and Jin (2004), among others, reveal a positive correlation between exports and growth. On the other hand, Harrison and Hanson (1999) and O'Rourke (2000) questioned the robust positive relationships between these two variables.

Tourism has been embraced as a strategic engine of growth for many small countries as a way to overcome the constraints of a small market and to foster rapid economic growth. The positive link between tourism and long-term economic growth is undergirded in the so-called tourism-led growth hypothesis (TLGH) (Chen and Chiou-Wei, 2009; Ridderstaat, Croes and Nijkamp, 2013). The TLGH suggests that tourism specialization is growth enhancing and therefore resources should be allocated to the tourism industry more than other economic sectors. Many countries, especially small island economies, have specialized in tourism following the promise of tourism 
as a positive factor in generating economic growth, jobs and business opportunities. They typically built their tourism product by developing their factors for production and focusing on increasing their permanent and transient population (tourists). This strategy has been applied in the Caribbean and the Mediterranean (Buswell, 2011; Croes, 2011).

However, according to mainstream economics, tourism is low in R\&D intensity, lacking therefore an important component to induce higher productivity and hence economic growth, according to the mainstream economics. Also, according to mainstream economics, mixing small size (small economies) with an economic activity lacking in high technological components would not work well according to mainstream economics. The advantage of larger markets over smaller markets, however, run counter to recent empirical studies that suggest that on average tourism specialized countries grow faster than others (Armstrong and Read 2001; Baldacchino and Milne, 2000; Bertram, 2004; Escaith, 2001; Jayawardena and Ramajeesinghh, 2003; Looney, 1989; Wint, 2002). Tourist specialized countries are small in size which suggests that factors other than technology may be at work propelling economic growth. Understanding these working factors are crucial for small economies to sustain growth and prioritize resources in the future.

With the exception of Seetanah (2011), few studies have investigated the relationship between tourism development and economic growth. However, Seetanah's study does not control for size potentially compromising the results of the study. This study fills the gap in the literature by specifically investigating growth differentials among small islands, and the impact of tourism specialization on growth. The purpose of this study is to assess whether small size affects economic performance as Smith argued. It further attempts to ascertain, in view of new empirical evidence contesting Smith's view, whether the pattern of specialization could better explain economic performance. The study uses data of a panel of twenty seven small islands and standard time series methods to answer both questions. The objective of this analysis is to reveal propositions. The study does not aim to make statistical generalization. It concludes that patterns of specialization are better suited to explain economic output differentials in small islands. Its main contribution is in explaining cross countries' differences among small countries themselves, which until recently have received only limited attention.

The term "small economies" has been used in different contexts in the literature, and different measures have been used to define "smallness", including population size, land area, and GDP. Population size can be considered to be the most popular measure (Armstrong and Read, 2001; Croes, 2011; Crowards, 2002; Demas, 1965; Escaith, 2001; Kuznets, 1960; Prasad, 2003; Streeten, 1993). Population and land area are proxies of the size of an economy's factor endowments. The most common proxy for market size is GDP. Throughout this study, the variable population measures economic size, and smallness references a population smaller than one and half million, following the definition of the Commonwealth Secretariat in 1997 (cited in Wignaraja et al., 2004) and Prasad (2003). Economic performance is defined in this study as the level of income per capita. Finally, openness is defined as the ratio export to GDP because one of the main reasons of engaging in tourism development is the generation of foreign exchange earnings to finance imports (Jackman, Lorde, Lowe and Alleyne, 2011; Sinclair and Stabler, 1997). 
The remainder of this article is organized as follows. Section I explores the issue of size as a factor in economic development, particularly as it relates to specialization in tourism. Section II examines the literature review pertaining to the economic performance of small economies. Section III reviews the questions related to structural and functional openness as variables in explaining income levels with particular emphasis on the Caribbean. Section IV controls for variables other than size and openness. Section V examines whether tourism specialization is growth enhancing. Section VI reviews the study's conclusions and their theoretical and practical implications.

\section{Conclusions and implications}

This study investigated whether tourism specialization affects economic performance of small islands. The findings of this study suggest that patterns of specialization can be growth enhancing. This contradicts the accepted tradition of economic development in the region as espoused by, among others, Lewis (1955) and Demas (1965). Growth and development were associated until recently with industrialization in both theoretical and empirical terms.

Compounded by theoretical frameworks, such as endogenous growth theories which exalted the virtues of high tech sectors over the "non-progressive" sectors such as tourism, the future of small countries did not appear bright (Copeland, 1991).

The empirical evidence in this study contradicts this pessimistic outlook. It suggests that small islands experienced stronger basic patterns of growth than many developed countries, especially where economies of scale are not an issue. The findings further suggest that tourism specialization is not harmful to growth, and in lieu of technological gaps and resource limitations, tourism specialization is a sound option. Size, a lack of complete sovereignty or independence and export orientation do not seem to affect to a greater degree the variance in the real per capita GDP.

Specifically, the study advances three propositions. First, patterns of specialization are better suited to explain economic output in small islands. Second, tourism specialization in small islands leverages returns to scale in the global markets and propels economic growth. And third, economic output differentials among small islands may not be exclusively explained by comparative advantage. Other factors, such as institutional realities and path dependence, may play a role in economic performance.

The findings of this study have three relevant implications. The first implication pertains to theory. While our findings indicate that tourism specialization matters for small islands, physical constraints at some point may limit the growth possibilities of small islands. In other words, small islands cannot grow forever based on more arrivals and increased population (volume). Increasing the numbers of tourists and inhabitants seems not feasible in sustaining growth. Arguably, tourism specialization under this condition could reveal diminishing returns, meaning that growth will fall with more tourists. Solving this conundrum is essentially a matter of productivity.

The second implication is that mainstream economics considers productivity as a side effect of capital. But throwing more capital where land and labor are scarce may not solve this paradox. 
The narrow interpretation of capital espoused by mainstream economics cannot explain the continued growth of small islands specialized in tourism. The conceptualization of capital requires focusing on ideas and the capacity to absorb new knowledge as significant drivers of productivity. Considering ideas as a relevant economic asset and determinant of economic growth could deepen the understanding of how small island destinations grew and have sustained economic growth over time. Instead of considering the effects of tourism specialization as inducing diminishing returns to the economy, tourism specialization has the potential and ability to propel the condition of increasing returns. Ideas and skilled labor thus matter in this respect, and they rest on policy.

Finally, the third implication is that tourism specialization is a matter of policy. Policy is about choice and choice is more than a matter of understanding the determinants of outcomes. While fundamentals stemming from comparative advantage (e.g., natural resources and human capital) may play an important role in economic performance, they will not exclusively determine what a country will produce or export. The production structure may be shaped by other factors such as institutional realities and the process of managing tourism specialization patterns. Also, the rate at which tourism specialization takes place matters. For example, the historical turning point that disrupted the existing political and economic balance in the former Netherlands Antilles is the attainment of status aparte of Aruba in 1986 (Croes, 2011). This critical juncture enabled Aruba to pursue a policy based on complete trade openness, unlike Curacao that continued to embrace a policy of import substitution and trade restriction. Thus, path dependency may have frustrated Curacao's growth opportunities compared to Aruba.

Small island destinations in general have followed the strategic pattern of enlarging markets through mass tourism. Their comparative advantage rested on the exploitation of natural resources (especially beaches). But tourism specialization may only be an enabling mechanism. If other policies create obstacles mitigating growth opportunities, then the gains from tourism specialization could be insignificant. Probably one plausible explanation for growth differentials among small island destinations might be the effective management of the rate of transformation in trade patterns (specialization in tourism) and dependency. We do not know yet which factors matter for trade patterns. This, however, is an issue that deserves closer scrutiny in future investigations.

Future research will determine whether higher terms of trade can be sustained and whether these higher terms of trade are directly related to higher quality of life. In other words, whether growth based on tourism specialization can be inclusive or whether such specialization patterns drive inequality. It is crucial for small island destinations to understand the dynamics of tourism specialization and terms of trade and whether specialization is able to spur continuous high return and higher quality of life. Empirically testing the reconceptualization of capital could increase the understanding of the determinants of higher and sustainable growth in tourism specialized small islands. If small island destinations specializing in tourism will be facing diminishing return at some point in time, it is critical to understand the conditions that would prompt that diminishing return. Determining these conditions, their sequence, and the time of occurrence prompts a deeper understanding of the dynamics of tourism specialization as it impacts growth prospects of small islands. 
